\title{
Assessment of local skin reactions with a sequential regimen of cryosurgery followed by ingenol mebutate gel, $0.015 \%$, in patients with actinic keratosis
}

This article was published in the following Dove Press journal:

Clinical, Cosmetic and Investigational Dermatology

16 December 2014

Number of times this article has been viewed

\author{
Gary Goldenberg' \\ Brian Berman ${ }^{2,3}$ \\ 'Department of Dermatology, Mount \\ Sinai School of Medicine, New York, \\ NY, ${ }^{2}$ Center for Clinical and Cosmetic \\ Research, Aventura, FL, ${ }^{3}$ Department \\ of Dermatology and Cutaneous \\ Surgery, University of Miami Miller \\ School of Medicine, Miami, FL, USA
}

\begin{abstract}
Lesion-directed and field-directed therapies are used to treat actinic keratosis (AK). Therapeutic approaches that combine both types of therapies may improve the successful elimination of AKs. A randomized, double-blind, vehicle-controlled study evaluated the safety, tolerability, and efficacy of topical field treatment with ingenol mebutate gel, $0.015 \%$, after cryosurgery to AKs on the face and scalp. Patients with 4-8 visible discrete AKs in a $25-\mathrm{cm}^{2}$ contiguous area received cryosurgery of all AKs at baseline. After a 3-week healing period, patients applied ingenol mebutate gel, $0.015 \%$, or vehicle gel once daily for 3 consecutive days to the treatment area. The incidence, severity, and time course of the development and resolution of local skin reactions were measured from baseline to week 11. Local skin reactions peaked shortly after completion of ingenol mebutate treatment and generally resolved within 2 weeks. The mean (95\% confidence interval) composite score (maximum range, $0-24)$ for these reactions was higher in patients with treatment of AKs on the face, 9.3 (8.5-10.1), as compared with the scalp, 5.8 (4.3-7.4). Erythema and flaking/scaling were the major contributors to the composite local skin reaction score. These results show that local skin reactions associated with ingenol mebutate treatment of the face or scalp are well tolerated after recent cryosurgery.
\end{abstract}

Keywords: ingenol mebutate gel, actinic keratosis, field therapy, local skin reaction

\section{Introduction}

Actinic keratosis (AK) is a common skin disease in older, fair-skinned people and is the consequence of cumulative exposure to ultraviolet light. The presence of $\mathrm{AK}$ is associated with an increase in the risk of invasive squamous cell carcinoma (SCC), although which specific AKs will progress to SCC cannot be predicted. The fact that the majority of clinically diagnosed SCCs originate from concomitant or contiguous $\mathrm{AKs}^{1-4}$ supports the importance of evaluation and treatment of these lesions. Cryosurgery is the most commonly used treatment for AK.${ }^{5,6}$ Cryosurgery fails to treat the field cancerization of perilesional skin, however, and thus $\mathrm{AK}$ recurrence rates are significant. ${ }^{7}$ The utilization of field-directed treatment after cryosurgery improves clearance rates for AK compared with cryosurgery alone. ${ }^{8-10}$ Unfortunately, many topical field therapies require application for several weeks, and patients with AK may not adhere completely to regimens of long duration. ${ }^{11}$ Ingenol mebutate gel is a topical treatment for AK that has demonstrated significant clinical efficacy in achieving sustained clearance of AKs. ${ }^{12,13}$ Treatment with ingenol mebutate is well tolerated, and adherence to the 2-day or 3-day regimen is high.
Correspondence: Gary Goldenbers Mount Sinai School of Medicine, 1428 Madison Ave, New York, NY 10029, USA

Tel + I 9172099940

Email garygoldenbergmd@gmail.com 
A recent study compared the safety and efficacy of ingenol mebutate gel, $0.015 \%$, with vehicle gel treatment started at 3 weeks after cryosurgery. ${ }^{14}$ The study involved 329 patients who had $4-8 \mathrm{AKs}$ in a $25-\mathrm{cm}^{2}$ area of the face or scalp. At 11 weeks after cryosurgery ( 8 weeks after topical treatment), the rate of complete clearance (no AKs present) was significantly higher in the ingenol mebutate group than in the vehicle group $(60.5 \%$ versus $49.4 \%$, respectively; $P=0.04$ ); the partial clearance rate ( $\geq 75 \%$ of baseline lesions) was also significantly higher with ingenol mebutate than with vehicle $(77.8 \%$ versus $67.3 \%$, respectively; $P=0.05) .{ }^{14}$ Adverse events related to ingenol mebutate were predominantly application-site conditions that were transient and generally mild to moderate in severity, with no evidence of added irritation resulting from recent cryosurgery. ${ }^{14}$

We conducted a subanalysis from this primary study to characterize the frequency, severity, and time course of local skin reactions (LSRs) separately for the face and the scalp to evaluate any differences in the reactions to ingenol mebutate at these separate anatomic sites.

\section{Materials and methods}

The methods for this randomized, double-blind, vehiclecontrolled Phase III study have been previously described in detail ${ }^{14}$ and are briefly summarized here. All patients were $\geq 18$ years of age and had 4-8 clinically typical, visible, discrete AKs within a contiguous $25-\mathrm{cm}^{2}$ area of the face or scalp. Enrollment was controlled so that approximately $80 \%$ and $20 \%$ of patients had face and scalp AK, respectively. At baseline (visit 1), all patients were randomized to one of two treatment groups in a blinded fashion; all patients received cryosurgery to all baseline AKs in the treatment area, in accordance with each investigator's normal practice. After approximately 3 weeks to allow for healing, patients applied topical ingenol mebutate gel, $0.015 \%$, or vehicle gel to the treatment area once daily for 3 consecutive days (beginning at visit 2). Short-term follow-up began at 1 day after the last application of the study medicine (visit 3 ), with a +3 -day window for the visit; follow-up visits occurred at week 5, 7, and 11 (visits 4-6) after cryosurgery. LSRs were assessed at all visits through week 11, and lesion counts were assessed at baseline, week 3, and week 11 (Figure 1). Patients were followed for 12 months. The LSRs were evaluated for six parameters (erythema, flaking/scaling, crusting, swelling, vesiculation/pustulation, and erosion/ulceration) and graded on a scale from 0 to 4 (higher numbers indicate greater severity), as previously described. ${ }^{12}$ The composite LSR score was the sum of the six individual scores and could range from 0 to 24 . All diagnoses and evaluations were made by a board-certified or board-eligible dermatologist.

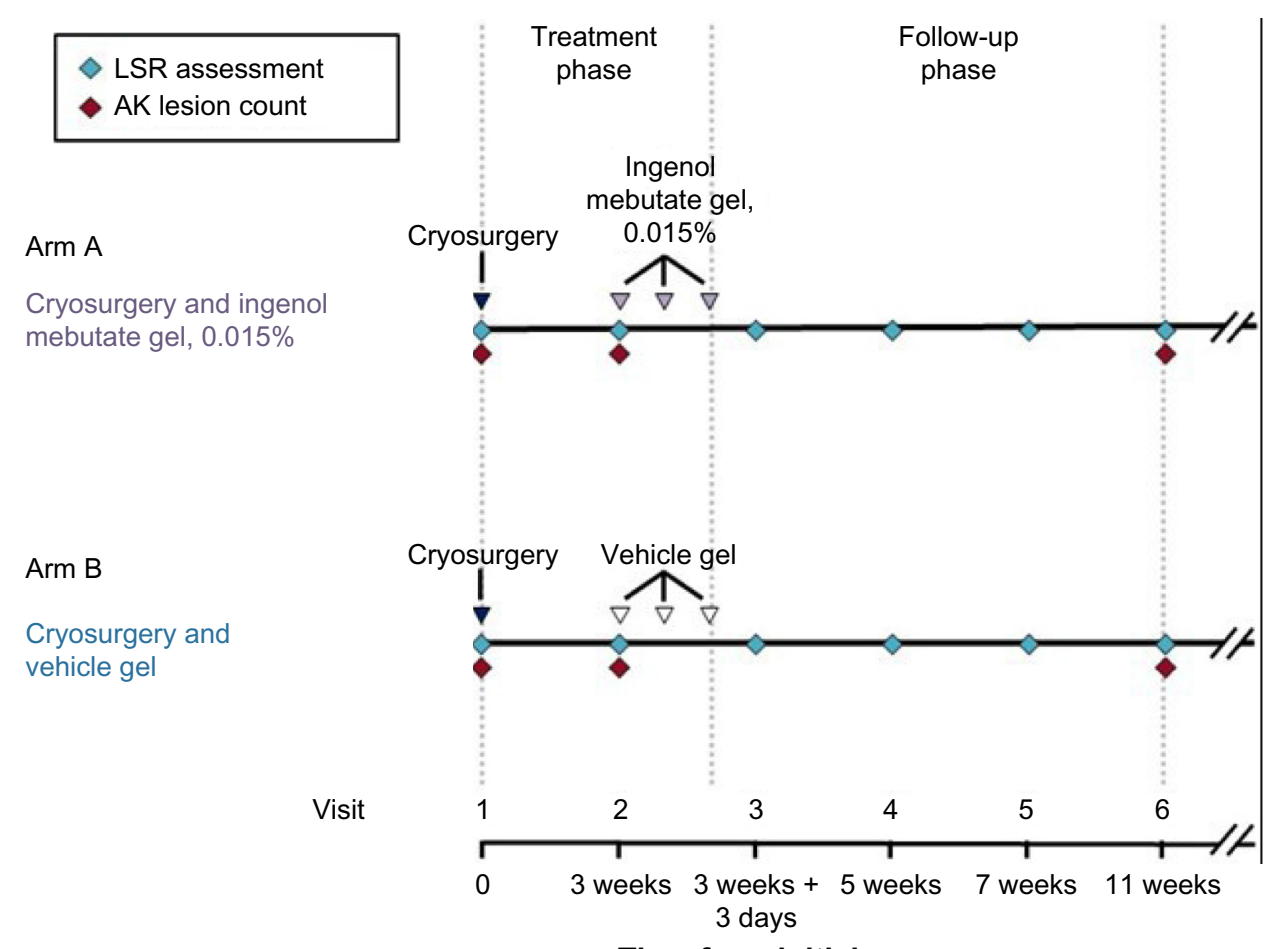

Time from initial cryosurgery

Figure I Study design

Abbreviations: AK, actinic keratosis; LSR, local skin reaction. 
The same dermatologist generally performed all examinations for individual patients.

\section{Results}

\section{Patient disposition and demographics}

Of the 329 patients enrolled in the study, 167 were randomized to ingenol mebutate gel, $0.015 \%$, and 162 to vehicle gel. ${ }^{14}$ The median age of the patients was 67 (range 34-89) years, and most patients (82.4\%) were male; median duration of AK history was 10.3 (range $0-55$ ) years, and $89.1 \%$ of patients had undergone previous cryosurgery for AK (data on file, LEO Pharma A/S, 2013). ${ }^{14}$ The baseline characteristics of the two treatment groups were similar (Table 1). Nine patients

Table I Patient characteristics at baseline

\begin{tabular}{|c|c|c|c|}
\hline Characteristic & $\begin{array}{l}\text { All } \\
\text { patients } \\
(\mathrm{N}=329)\end{array}$ & $\begin{array}{l}\text { Ingenol } \\
\text { mebutate } \\
(n=167)\end{array}$ & $\begin{array}{l}\text { Vehicle } \\
(n=162)\end{array}$ \\
\hline Male patients (\%) & 82.4 & 82.6 & 82.1 \\
\hline Mean age (years) & 67.0 & 66.7 & 67.4 \\
\hline \multicolumn{4}{|l|}{ Race (\%) } \\
\hline Caucasian & 100 & 100 & 100 \\
\hline \multicolumn{4}{|l|}{ Ethnicity (\%) } \\
\hline Not Hispanic or Latino & 98.8 & 98.2 & 99.4 \\
\hline Hispanic or Latino & 1.2 & 1.8 & 0.6 \\
\hline \multicolumn{4}{|l|}{ Skin type } \\
\hline I & 15.2 & 15.0 & 15.4 \\
\hline II & 48.0 & 46.7 & 49.4 \\
\hline III & 27.7 & 28.7 & 26.5 \\
\hline IV & 8.2 & 8.4 & 8.0 \\
\hline $\mathrm{V}$ & 0.9 & 1.2 & 0.6 \\
\hline \multicolumn{4}{|l|}{ AK characteristics } \\
\hline Mean AK lesion count & - & 5.74 & 5.82 \\
\hline \multicolumn{4}{|l|}{ Location of AK lesions } \\
\hline Face & 80.5 & 78.4 & 82.7 \\
\hline Scalp & 19.5 & 21.6 & 17.3 \\
\hline Positive skin cancer history (\%) & 47.1 & 49.7 & 44.4 \\
\hline \multicolumn{4}{|l|}{ AK treatment history } \\
\hline Mean duration of AK (years) & 11.9 & 12.9 & I I.0 \\
\hline \multicolumn{4}{|l|}{ Previous treatment (\%) } \\
\hline $\begin{array}{l}\text { Cryosurgery/liquid } \\
\text { nitrogen }\end{array}$ & 89.1 & 88.6 & 89.5 \\
\hline Excision/curettage & 15.5 & 13.2 & 17.9 \\
\hline 5-Fluorouracil & 18.5 & 16.8 & 20.4 \\
\hline Imiquimod & 17.3 & 15.0 & 19.8 \\
\hline Diclofenac & 8.8 & 9.6 & 8.0 \\
\hline Photodynamic therapy & 14.6 & 15.0 & 14.2 \\
\hline Retinoids & 1.5 & 1.2 & 1.9 \\
\hline $\begin{array}{l}\text { Ingenol mebutate (trunk } \\
\text { and extremities) }\end{array}$ & 3.3 & 3.0 & 3.7 \\
\hline Other & 6.7 & 7.2 & 6.2 \\
\hline
\end{tabular}

Note: Modified with permission from Berman B, Goldenberg G, Hanke CW, et al. Efficacy and safety of ingenol mebutate $0.015 \%$ gel 3 weeks after cryosurgery of actinic keratosis: I I-week results. J Drugs Dermatol. 20 I4;। 3(2): I54-160. ${ }^{14}$ Copyright (c) 2014.

Abbreviation: AK, actinic keratosis. randomized to ingenol mebutate and 12 patients randomized to vehicle withdrew from the study following cryosurgery without having applied any topical treatment. ${ }^{14}$ Nearly all of the patients who continued in the study applied all three doses of topical treatment. ${ }^{14}$ Of the 158 patients who entered the topical treatment phase of the study and were assigned to ingenol mebutate at randomization, 155 completed the study through visit 6 (week 11). ${ }^{14}$

\section{Local skin reactions}

At baseline, the mean composite LSR score was similar between the ingenol mebutate and vehicle groups. After cryosurgery, the mean composite LSR scores decreased slightly in all groups over the 3-week period prior to topical field treatment. Shortly after ingenol mebutate treatment, at visit 3 , the mean (95\% confidence interval) composite LSR score in patients who treated the face, 9.3 (8.5-10.1; $n=120)$, was higher than the composite score in patients who treated the scalp, 5.8 (4.3-7.4; n=36; Figure 2A and B). The median and upper limits of the range of composite LSR scores at visit 3 were also higher for the face than the scalp (Table 2). In the subset of patients treated with ingenol mebutate in which visit 3 occurred exactly 1 day after the last application, the composite score was 10.1 (8.9-11.3) after treatment of the face $(n=57)$ and $5.2(3.4-7.0)$ after treatment of the scalp $(n=18)$. The time course of each component reaction was similar to the time course of the composite LSR score (Figure 3A and B). At visit 4, the values for the mean, standard deviation, and median for each of the six component reactions were all less than 1 . Erythema and flaking/scaling were the major contributors to the composite LSR score for patients treating the face or the scalp (Figures 3A, B, 4A, and B). Erythema was 30\% (2.8/9.3) and 33\% (1.92/5.8) of the mean composite score for the face and scalp, respectively. Flaking/scaling was 25\% (2.36/9.3) and 22\% (1.28/5.8) of the composite score for the face and scalp, respectively. At week 5, 2 weeks after topical treatment, the mean composite LSR score in the ingenol mebutate group for both the face and the scalp returned to a score similar to that of visit 2 (Figure 2A and B). Although the component and composite LSR scores of visit 3 were higher for the face than the scalp, the time course of LSR resolution was similar.

At the time of peak LSR development (visit 3), grade 4 component LSRs were infrequent. Of patients who treated the face, $27.5 \%, 13.3 \%$, and $11.7 \%$ had grade 4 reactions of erythema, flaking/scaling, and crusting reactions, respectively (Figure 5A); among patients treating the scalp, the corresponding frequencies were $5.6 \%, 2.8 \%$, and $2.8 \%$. For the parameters 

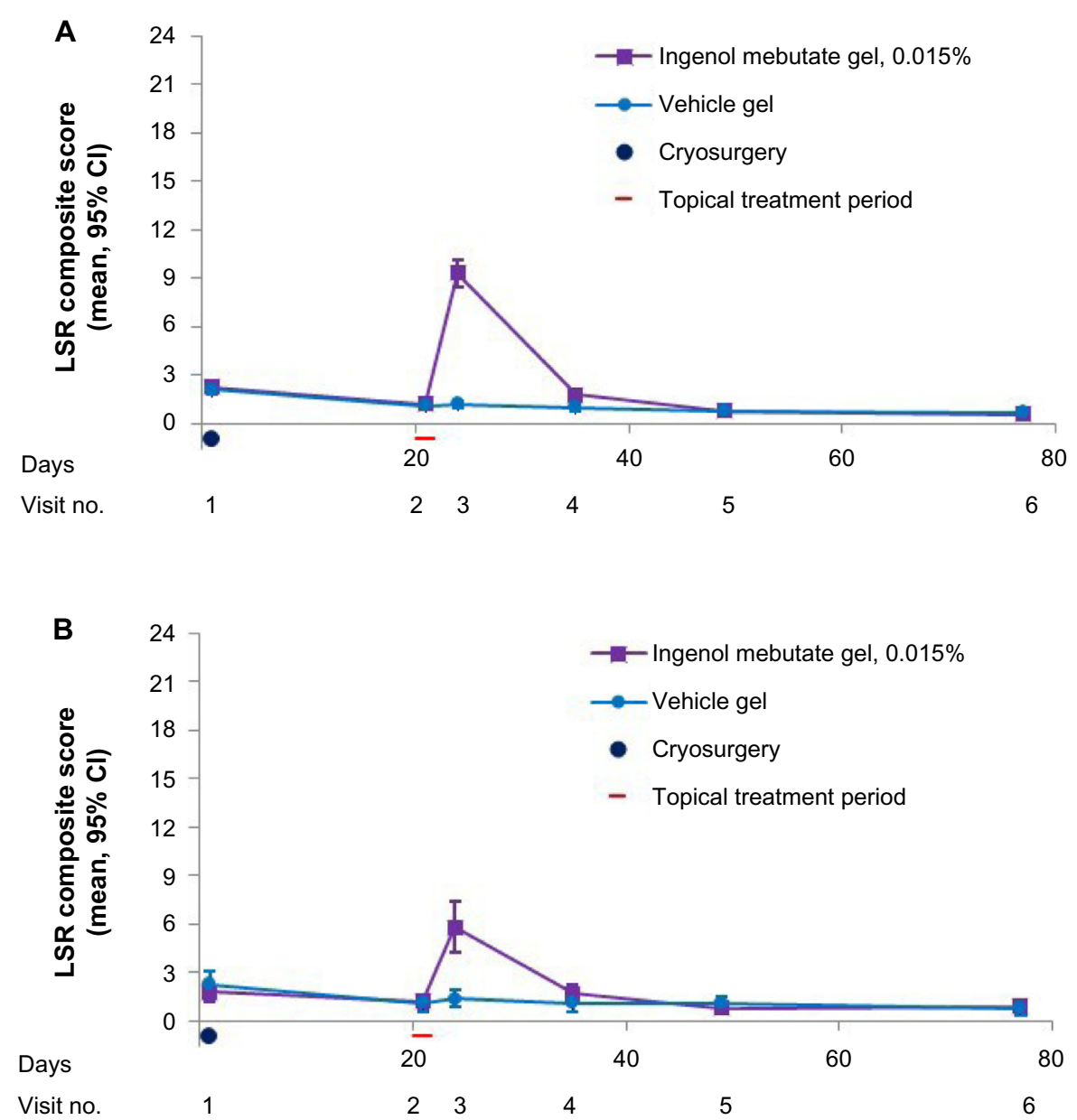

Figure 2 Mean composite LSR score $(95 \% \mathrm{Cl})$ by visit, for the LSR analysis set. (A) Data shown for all patients who applied topical gel to the face and had LSR assessments: ingenol

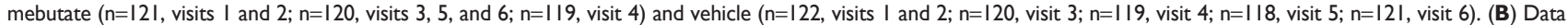
shown for all patients who applied topical gel to the scalp and had LSR assessments: ingenol mebutate ( $\mathrm{n}=36$, all visits) and vehicle ( $\mathrm{n}=28$, visits I, 2, 3, 4, and 5; $\mathrm{n}=27$, visit 6).

Abbreviations: $\mathrm{Cl}$, confidence interval; LSR, local skin reaction.

of swelling, vesiculation/pustulation, and erosion/ulceration, grade 4 reactions occurred in $<9 \%$ and $<3 \%$ of patients treating the face and scalp, respectively (Figure 5A and B).

Photographs of two patients taken at each of the study visits show the treatment site, development of LSRs, and

Table 2 Composite LSR score by visit and anatomic location for patients treated with ingenol mebutate gel, $0.015 \%$

\begin{tabular}{|c|c|c|c|c|c|}
\hline \multirow[t]{2}{*}{ Visit } & \multirow[t]{2}{*}{ Time } & \multicolumn{2}{|l|}{ Face $^{\mathbf{a}}$} & \multicolumn{2}{|l|}{ Scalp } \\
\hline & & $\begin{array}{l}\text { Mean } \\
\text { (SD) }\end{array}$ & $\begin{array}{l}\text { Median } \\
\text { (range) }\end{array}$ & $\begin{array}{l}\text { Mean } \\
\text { (SD) }\end{array}$ & $\begin{array}{l}\text { Median } \\
\text { (range) }\end{array}$ \\
\hline I & Day I & $2.3(2.0)$ & $2.0(0-7)$ & I.8 (I.7) & $2.0(0-6)$ \\
\hline 2 & Week 3 & I.2 (I.3) & $\mathrm{I} .0(0-6)$ & I.2 (I.3) & $1.0(0-5)$ \\
\hline 3 & $\begin{array}{l}\text { Week } 3+ \\
3 \text { days }\end{array}$ & $9.3(4.5)$ & $9.0(0-20)$ & $5.8(4.6)$ & $5.0(0-17)$ \\
\hline 4 & Week 5 & $1.8(1.9)$ & I.0 (0-II) & I.7 (I.6) & I.0 (0-5) \\
\hline 5 & Week 7 & $0.8(0.9)$ & $0.5(0-4)$ & $0.8(1.0)$ & $0.0(0-4)$ \\
\hline 6 & Week II & $0.6(0.9)$ & $0.0(0-3)$ & $0.9(1.2)$ & $0.0(0-5)$ \\
\hline
\end{tabular}

Notes: ${ }^{a} n=|2|$, visits $\mid$ and $2 ; n=\mid 20$, visits 3,5 , and $6 ; n=\mid 19$, visit 4 . ${ }^{b} n=36$, all visits. Abbreviations: SD, standard deviation; LSR, local skin reaction. resolution of LSRs at the time of visit 4, 2 weeks after the application of ingenol mebutate. Patient 1 treated a portion of the cheek (Figure 6) and patient 2 treated a portion of the forehead (Figure 7).

\section{Discussion}

Ingenol mebutate gel, $0.015 \%$, is a short-duration field treatment for AK involving once-daily application for 3 consecutive days to treat the face and scalp. In this study, ingenol mebutate was applied to a $25-\mathrm{cm}^{2}$ area in which recent cryosurgery had been used to treat 4-8 clinically diagnosed AKs. LSRs developed rapidly after application of ingenol mebutate gel, peaked in severity shortly after completion of treatment, and returned to near baseline levels 2 weeks later. This was similar to the time course of the development and resolution of LSRs in Phase III studies of ingenol mebutate gel monotherapy. ${ }^{12}$

The severity of LSRs in this study was also similar to the severity in the ingenol mebutate gel monotherapy studies. ${ }^{12}$ 


\section{A}

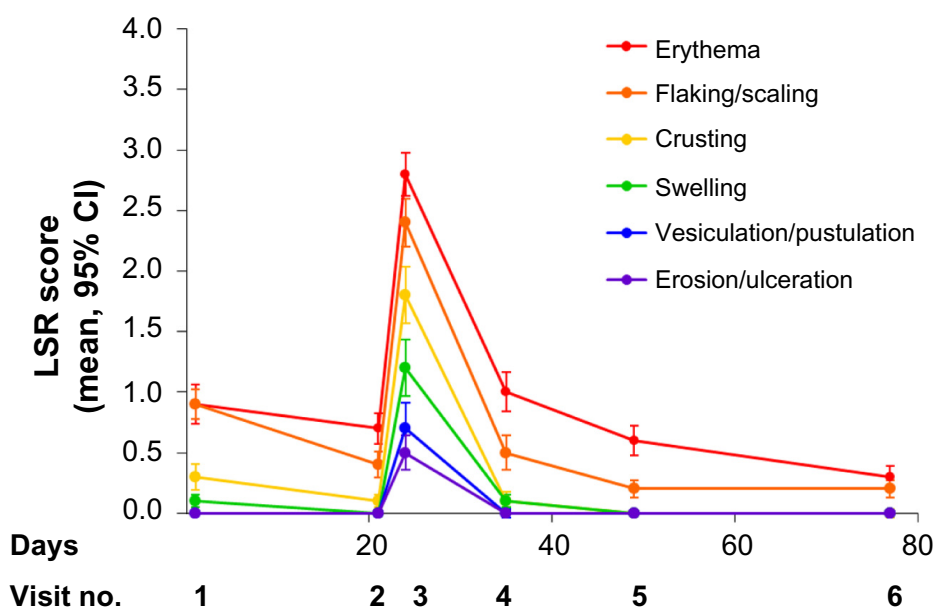

B

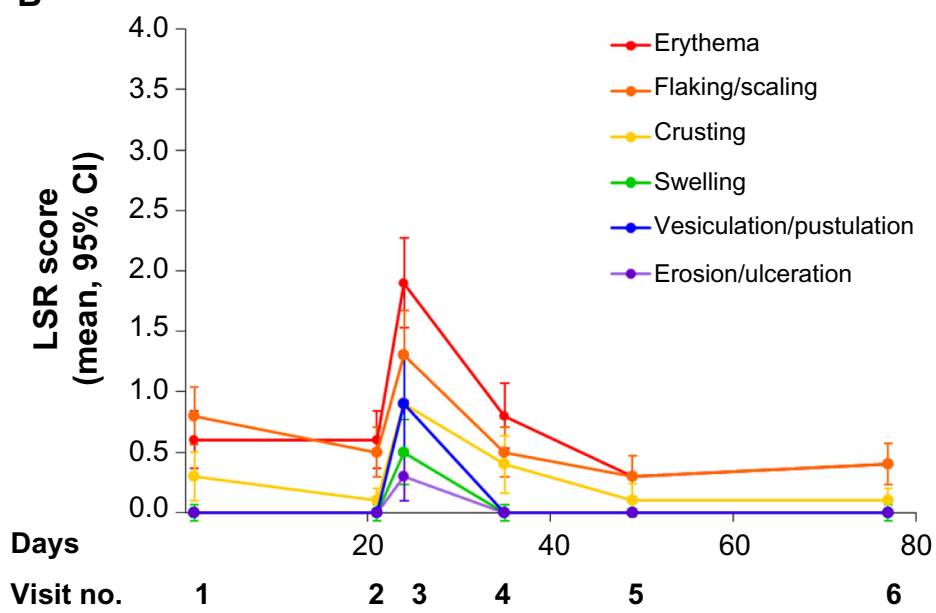

Figure 3 Mean component LSR score $(95 \% \mathrm{Cl})$ by visit, for the LSR analysis set for each of six individual reactions on the (A) face or (B) scalp. Numbers of patients are the numbers specified in the ingenol mebutate groups.

Abbreviations: $\mathrm{Cl}$, confidence interval; LSR, local skin reaction.
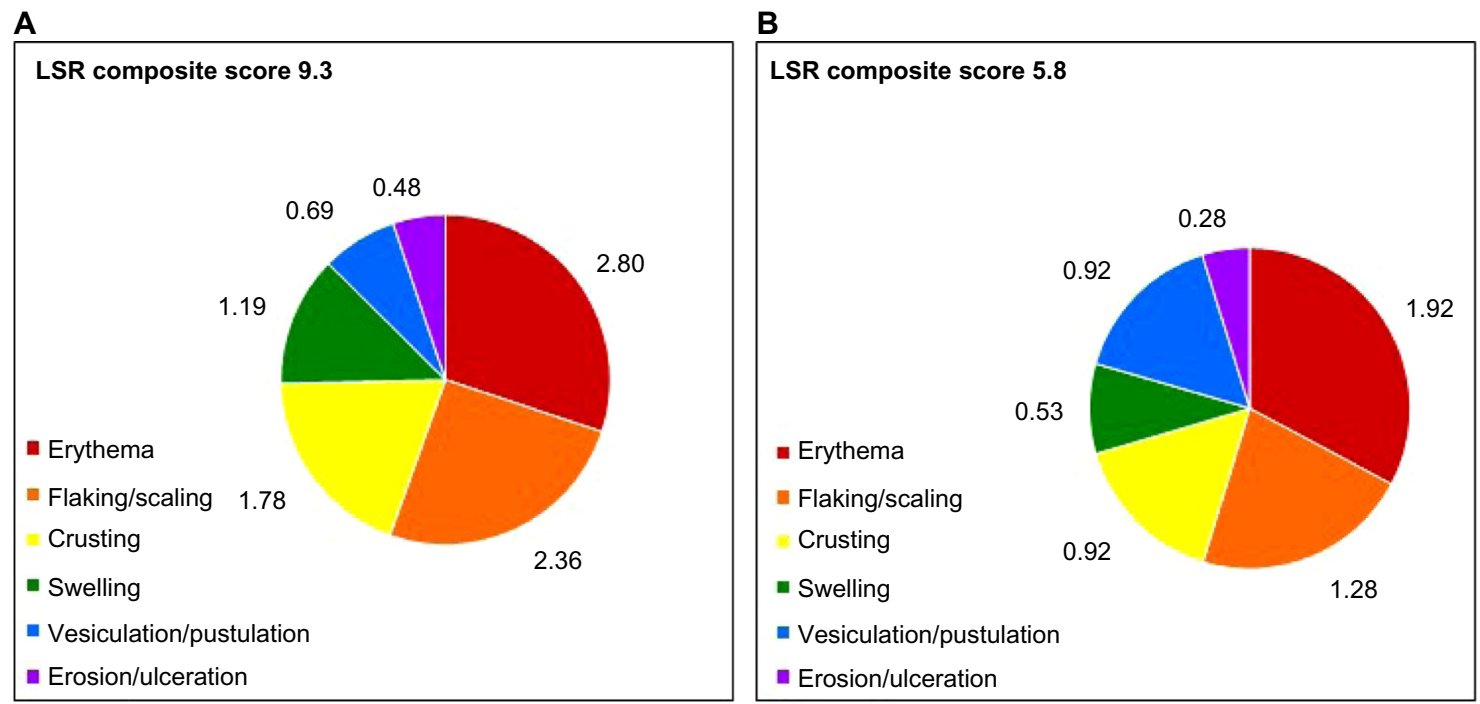

Figure 4 Individual components (mean scores) of the LSR composite scores at visit 3 for $(\mathbf{A})$ the face $(n=120)$ and $(\mathbf{B})$ the scalp $(n=36)$. Abbreviation: LSR, local skin reaction. 


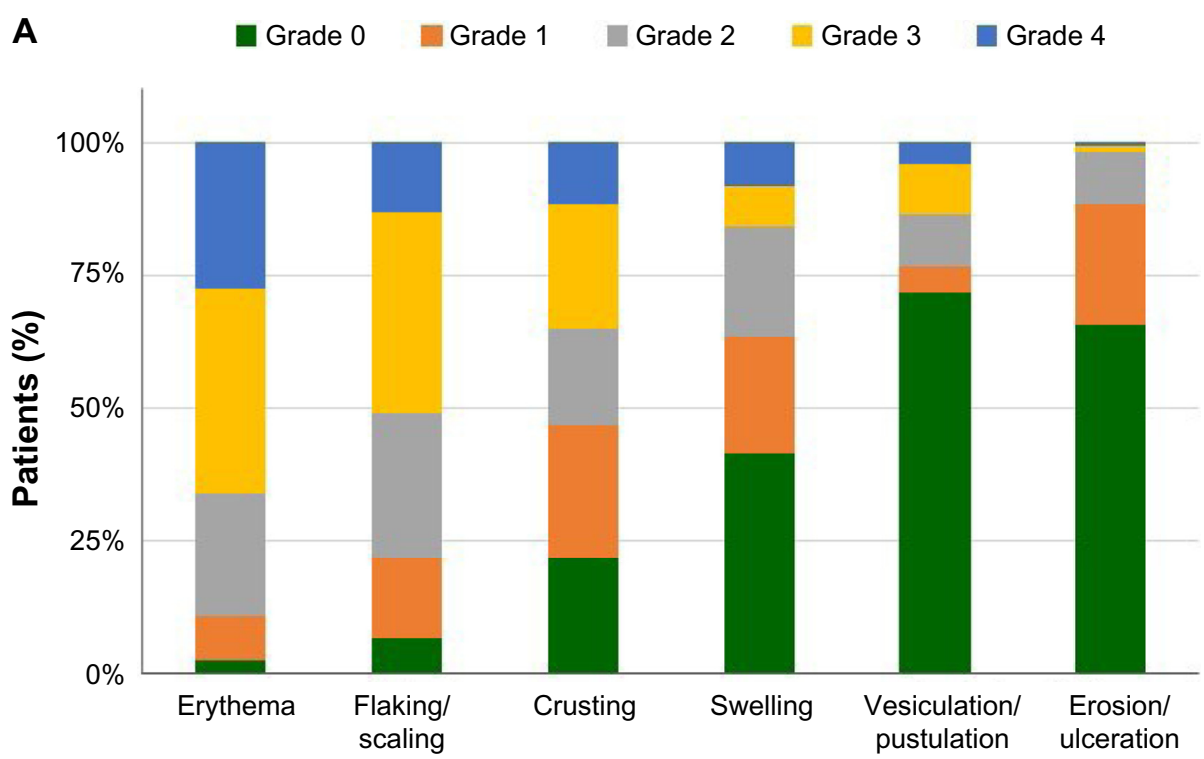

\section{B $\quad$ Grade 0 Grade $1 \square$ Grade $2 \square$ Grade $3 \square$ Grade 4}

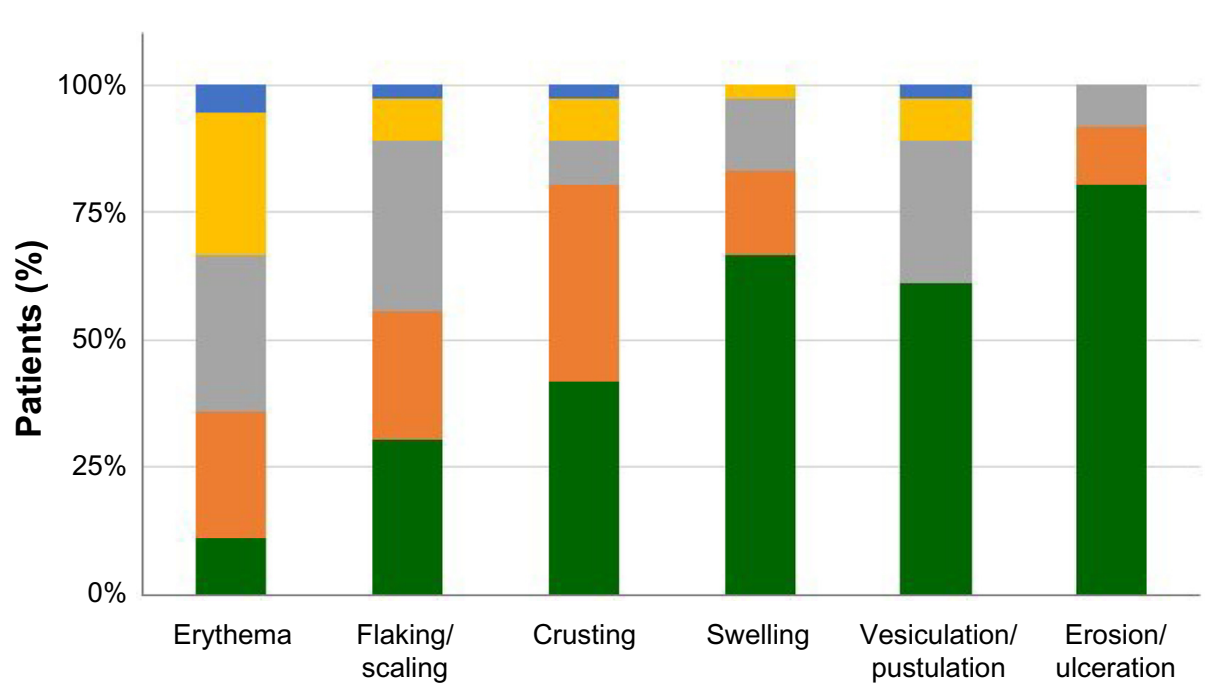

Figure 5 Individual LSRs experienced at visit 3 by patients treated on the $(\mathbf{A})$ face $(n=120)$ or $(\mathbf{B})$ scalp $(n=36)$ with ingenol mebutate, graded on a scale of 0 to 4 , with higher numbers indicating greater severity.

Abbreviation: LSRs, local skin reactions.

At 1 day after completion of sequential therapy on the face, the mean composite LSR score in the present study was 10.1 (range 8.9-11.3; $\mathrm{n}=57$ ) compared with 9.3 (range 8.7-9.8; $\mathrm{n}=217$ ) in the ingenol mebutate monotherapy study (data on file, LEO Pharma A/S, 2013). For the scalp, these values were 5.2 (range $3.4-7.0 ; n=18)$ and $6.7(5.7-7.7 ; n=56$ ) for sequential therapy and monotherapy, respectively (data on file, LEO Pharma A/S, 2013). In both studies, erythema and flaking/crusting were the major contributors to the composite LSR score.

The finding of higher LSR scores on the face than the scalp may be the result of multiple factors. The skin of the face is thinner and has fewer hair follicles than the skin of the scalp. Also, AKs on the scalp are generally thicker than those seen on the face, which may restrict absorption of ingenol mebutate on the scalp. If the severity of LSRs is related to selective absorption by abnormal skin, the degree of absorption into the abnormal AKs may be another differentiating factor.

Studies of ingenol mebutate in cancer cells suggest that transformed cells are more sensitive to its biological effects than are normal, differentiated keratinocytes. ${ }^{15}$ In the present study, the presence of a composite LSR score after sequential therapy that was similar to the composite score after ingenol 


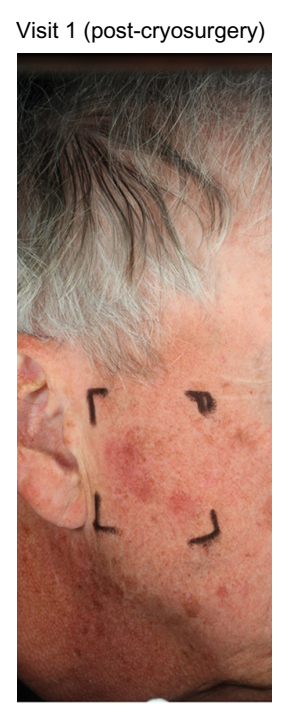

Visit 2

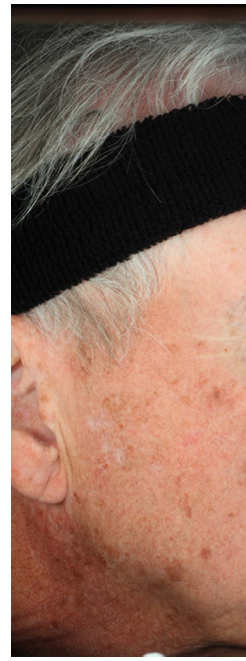

Visit 4

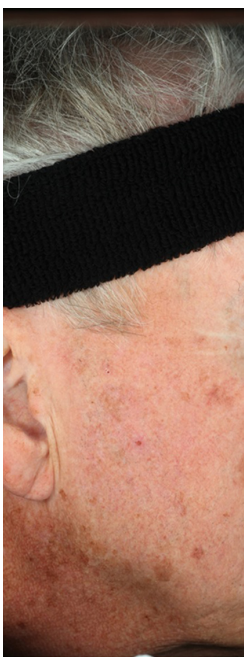

Visit 5

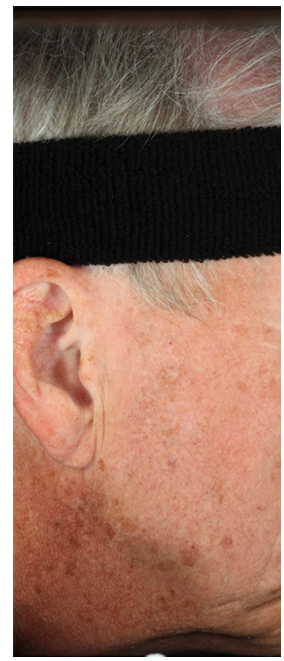

Visit 3

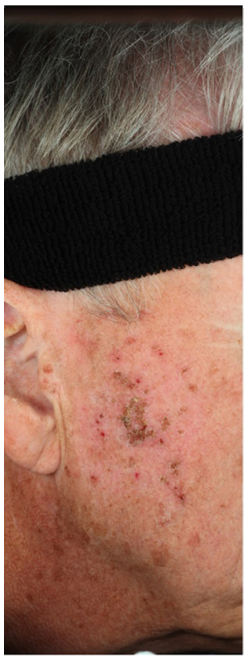

Visit 6

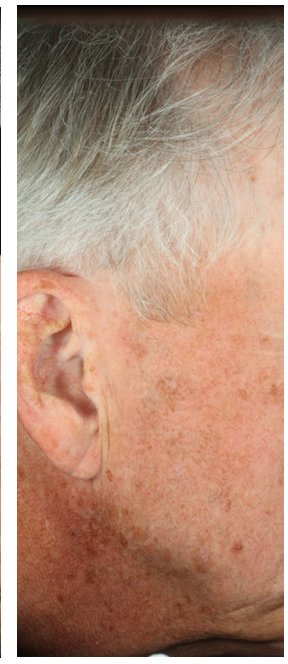

Figure 6 Patient I.

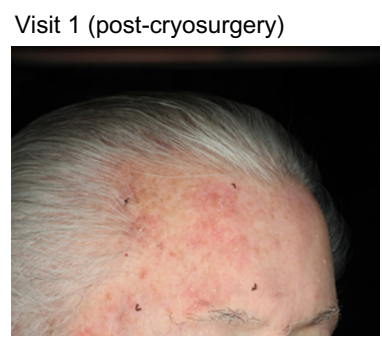

Visit 4

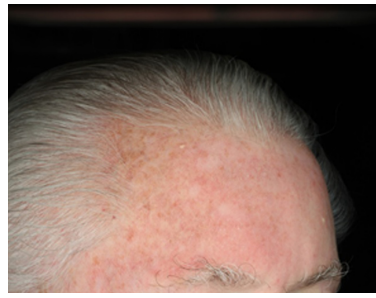

Visit 2

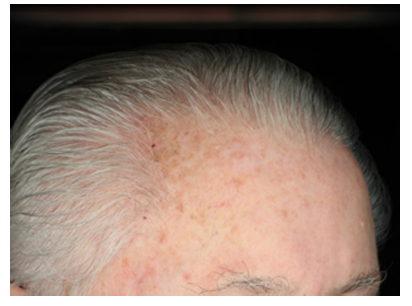

Visit 5

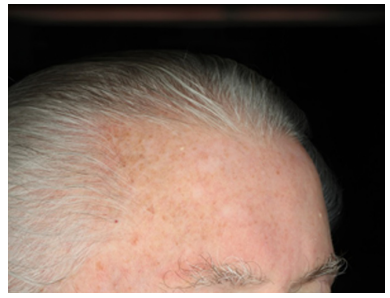

Visit 3

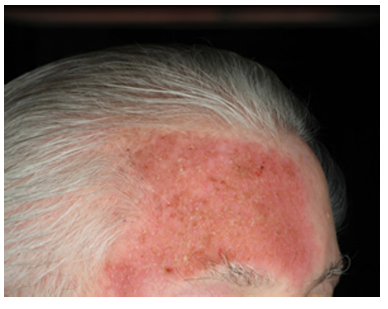

Visit 6

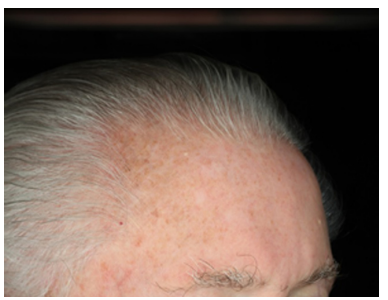

Figure 7 Patient 2. 
mebutate monotherapy suggests that subclinical lesions may be present in the perilesional, sun-damaged skin surrounding the visible lesions treated with cryosurgery. These subclinical lesions may also be targeted by the biological effects of ingenol mebutate.

In conclusion, these data indicate that the LSRs produced on the face and scalp with topical ingenol mebutate gel, $0.015 \%$, following recent cryosurgery were well tolerated.

\section{Acknowledgments}

This paper is published on behalf of the members of the Data Oversight Committee for Clinical Trial NCT01541553, comprising Brian Berman, Gary Goldenberg, C William Hanke, Neil Swanson, Stephen Tyring, and W Philip Werschler. Editorial assistance was provided by Tanya MacNeil of $p$-value communications.

\section{Disclosure}

GG is an investigator for LEO Pharma Inc., Medicis, and PharmaDerm. He is also a consultant and speaker for LEO Pharma Inc. and Medicis. BB has served as an advisor for DUSA, Graceway, LEO Pharma Inc., Medicis, PharmaDerm, and Valeant and is a consultant for all of them except PharmaDerm. He is also an investigator and speaker for DUSA, LEO Pharma Inc., and Medicis, as well as a speaker for PharmaDerm and Valeant.

\section{References}

1. Criscione VD, Weinstock MA, Naylor MF, et al. Actinic keratoses: natural history and risk of malignant transformation in the Veterans Affairs Topical Tretinoin Chemoprevention Trial. Cancer. 2009;115(11): 2523-2530.

2. Czarnecki D, Meehan CJ, Bruce F, Culjak G. The majority of cutaneous squamous cell carcinomas arise in actinic keratoses. J Cutan Med Surg. 2002;6(3):207-209.
3. Mittelbronn MA, Mullins DL, Ramos-Caro FA, Flowers FP. Frequency of pre-existing actinic keratosis in cutaneous squamous cell carcinoma. Int J Dermatol. 1998;37(9):677-681.

4. Hurwitz RM, Monger LE. Solar keratosis: an evolving squamous cell carcinoma. Benign or malignant? Dermatol Surg. 1995;21(2):184.

5. Halpern AC, Hanson LJ. Awareness of, knowledge of and attitudes to nonmelanoma skin cancer (NMSC) and actinic keratosis (AK) among physicians. Int J Dermatol. 2004;43(9):638-642.

6. Balkrishnan R, Cayce KA, Kulkarni AS, et al. Predictors of treatment choices and associated outcomes in actinic keratoses: results from a national physician survey study. J Dermatolog Treat. 2006;17(3): $162-166$.

7. Krawtchenko N, Roewert-Huber J, Ulrich M, et al. A randomised study of topical 5\% imiquimod vs topical 5-fluorouracil vs cryosurgery in immunocompetent patients with actinic keratoses: a comparison of clinical and histological outcomes including 1-year follow-up. $\mathrm{Br} J$ Dermatol. 2007;157(Suppl 2):34-40.

8. Goldenberg G, Linkner RV, Singer G, Frankel A. An investigatorinitiated study to assess the safety and efficacy of imiquimod $3.75 \%$ cream when used after cryotherapy in the treatment of hypertrophic actinic keratoses on dorsal hands and forearms. J Clin Aesthet Dermatol. 2013;6(2):36-43.

9. Jorizzo JL, Markowitz O, Lebwohl MG, et al. A randomized, doubleblinded, placebo-controlled, multicenter, efficacy and safety study of $3.75 \%$ imiquimod cream following cryosurgery for the treatment of actinic keratoses. J Drugs Dermatol. 2010;9(9):1101-1108.

10. Berlin JM, Rigel DS. Diclofenac sodium 3\% gel in the treatment of actinic keratoses postcryosurgery. J Drugs Dermatol. 2008;7(7):669-673.

11. Shergill B, Zokaie S, Carr AJ. Non-adherence to topical treatments for actinic keratosis. Patient Prefer Adherence. 2013;8:35-41.

12. Lebwohl M, Swanson N, Anderson LL, et al. Ingenol mebutate gel for actinic keratosis. $N$ Engl J Med. 2012;366(11):1010-1019.

13. Lebwohl M, Shumack S, Stein Gold L, et al. Long-term follow-up study of ingenol mebutate gel for the treatment of actinic keratoses. JAMA Dermatol. 2013;149(6):666-670.

14. Berman B, Goldenberg G, Hanke CW, et al. Efficacy and safety of ingenol mebutate $0.015 \%$ gel 3 weeks after cryosurgery of actinic keratosis: 11-week results. J Drugs Dermatol. 2014;13(2):154-160.

15. Stahlhut M, Bertelsen M, Hoyer-Hansen M, et al. Ingenol mebutate: induced cell death patterns in normal and cancer epithelial cells. $J$ Drugs Dermatol. 2012;11(10):1181-1192.
Clinical, Cosmetic and Investigational Dermatology

\section{Publish your work in this journal}

Clinical, Cosmetic and Investigational Dermatology is an international, peer-reviewed, open access, online journal that focuses on the latest clinical and experimental research in all aspects of skin disease and cosmetic interventions. All areas of dermatology will be covered; contributions will be welcomed from all clinicians and

\section{Dovepress}

basic science researchers globally. This journal is indexed on CAS The manuscript management system is completely online and includes a very quick and fair peer-review system, which is all easy to use. Visit http://www.dovepress.com/testimonials.php to read real quotes from published authors. 